\title{
Algorithm Analysis and Research on Highway Road Network
}

\author{
Yun Zhang \\ Yunnan Communications Investment \& Construction Group CO.LTD, Kunming 250061, China.
}

\author{
Keywords: Traffic Flow Data, Travel Speed, Road Network Condition, Algorithm Model.
}

\begin{abstract}
As for Highway, the paper put forward a kind of algorithm model via using the data from vehicle detectors in the fields and data of ETC and manual Charging system in Tolling stations. Based on it, the paper gives off algorithm design and are implemented. The applications on road traffic management show the results are satisfactory.
\end{abstract}

\section{Introduction}

With China's entry into the automobile era, the urban family and the rural families will take the vehicle as the main mean of transportation. The number of cars on the road is increasing, which brings great pressure to the road traffic. Although all provinces in the country are speeding up the construction of highway mileage, it is still unable to alleviate the pressure of road traffic. On holidays, the congestion of the freeway is particularly serious. At present, most provinces are carrying out intellectualization for alleviating road traffic jams, hoping to change people's way of travel by means of information construction, so as to improve the efficiency of road network and reduce the unbalanced use of roads, and have achieved some results in a certain extent. In particular, the use of variable message signs display system provides a certain information service to the driver. At present, most of the route guidance is to provide the condition of the road network of the road ahead and the surrounding road to the driver through the variable message signs set on field road, which display the three colors with red, yellow and green, guiding the diver to choose the reasonable driving path, where, the green is smooth, the yellow is crowded and red is congestion [1-6, 8,9]. At present, a lot of research work has been done about the determination of smooth, crowding and congestion. Professors, researchers, business technicians and so on have done many research works. The main results are mostly urban traffic $[1,4,5,7]$, there are few studies on highway network traffic. Taking the highway as the research object, based on the data of tolling data and the data from fixed detector, this article studies the highway road network state model, algorithm, the results of the study are applied to the network state released of the Yun Nan highway road network, it shows the significant effect.

\section{Some Definitions}

The definition of the natural section of the highway is usually the starting point or the end of the natural section with the confluence or diverging point of the road traffic flow. According to the characteristics of the highway, the confluence and distributary point generally take the toll station and interchange as cutting points.

The definition of highway release section: generally taking the toll station of the freeway as the starting point or the end. The link between the two adjacent toll stations on the expressway is issued as a release section. The length of the release section is the same as the distance between the adjacent toll stations. According to the definition of the toll station of the freeway, the toll station can be a virtual toll station.

The figure is shown as follow: 


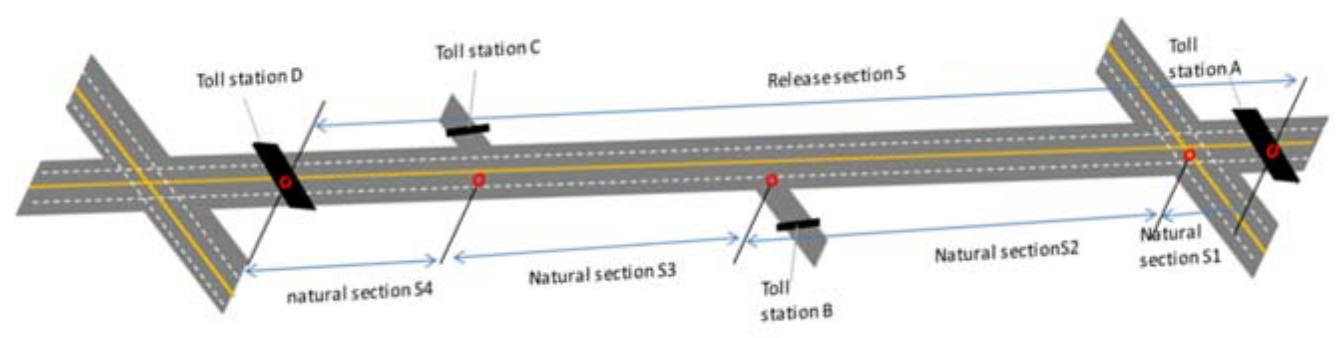

Fig 1. Definition of Release Section and Natural Section

The figure includes four natural sections, a release section and four toll stations, and a release section consists of four natural sections.

\section{Model and Algorithms}

The highway network is composed of several release sections. This paper will determine the state of the whole road network by studying the state of the released sections, which is the basis for the release of the road network status. In general, the state of the release section is determined by the service level, traffic flow and travel speed. In this paper, the travel speed is used as a criterion for determining the state of the section. The speed of the highway is defined in accordance with the following three stages.

Table1. Three-Level State Definition

\begin{tabular}{|c|c|c|c|}
\hline state & congestion & crowd & smooth \\
\hline Travel speed $\mathrm{V}(\mathrm{km} / \mathrm{h})$ & $\mathrm{V}<=40$ & $40<\mathrm{V}<=60$ & $60<\mathrm{V}$ \\
\hline
\end{tabular}

\subsection{Model}

It is assumed that a microwave vehicle detector, a video event detection device, and a toll collection data of a toll station, and two types of passenger cars and one dangerous goods vehicle's GPS data. The algorithm model is as follows.

Where

$$
\begin{gathered}
V F B, F S=\min (V T, L 1, V T, L 2, V T, L 3, V T, L 4) \operatorname{orf}(V T, L 1, V T, L 2,, V T, L 3,, V T, L 4, \\
\mu T, L 1, \mu T, L 2, \mu T, L 3, \mu T, L 4)
\end{gathered}
$$

$$
\begin{gathered}
V T, L 1=f(V T-1, L 1, V F C, L 1, V A I D, L 1, V W A, L 1, V T O, L 1, \lambda T-1, L 1, \lambda F C, L 1, \\
\lambda A I D, L 1, \lambda W A, L 1, \lambda T O, L 1) \\
V T, L 2=f(V T-1, L 2, V F C, L 2, V A I D, L 2, V W A, L 2, V T O, L 2, \lambda T-1, L 2, \lambda F C, L 2, \lambda A I D, L 2, \\
\lambda W A, L 2, \lambda T O, L 2) ; \\
V T, L 3=f(V T-1, L 3, V F C, L 3, V A I D, L 3, V W A, L 3, V T O, L 3, \lambda T-1, L 3, \lambda F C, L 3, \lambda A I D, L 3, \\
\lambda W A, L 3, \lambda T O, L 3) ; \\
V T, L 4=f(V T-1, L 4, V F C, L 4, V A I D, L 4, V W A, L 4, V T O, L 4, \lambda T-1, L 4, \lambda F C, L 4, \lambda A I D, L 4, \\
\lambda W A, L 4, \lambda T O, L 4) ;
\end{gathered}
$$

Where,

VFC denotes the speed of two types of passenger cars and one dangerous goods vehicle;

VAID denotes the speed of the video event detection device;

VWA denotes speed of microwave vehicle detector;

VTO denotes the travel speed calculated from toll station;

$$
\lambda T-1, L i+\lambda F C, L i+\lambda A I D, L i+\lambda W A, L i+\lambda T O, L i=1, i=1,2,3,4
$$




\subsection{Algorithms}

$$
\mu T, L 1+\mu T, L 2+\mu T, L 3+\mu T, L 4=1 .
$$

According to the above calculation model, the algorithm analysis is given below. The whole system's algorithm is divided into the following steps:

Step 1: calculate the speed of each natural section.

Calculate the speed of each natural section according to the above formula (2) - (6).

Step 2: calculate the speed of each release section.

It will be calculated according to the above formula (1), (7).

Step 3: determine the status of each release segment.

When speed $\mathrm{VFB}<40 \mathrm{~km} / \mathrm{h}$, it shows red; when $40 \mathrm{~km} / \mathrm{h}<\mathrm{VFB}<60 \mathrm{~km} / \mathrm{h}$, it shows yellow; when $60 \mathrm{~km} / \mathrm{h}<\mathrm{VFB}$, it shows green.

When you can't get the speed value, check whether there is a traffic incident, if yes, then set to red, otherwise, set to green.

\subsection{Application Analysis}

The following is the speed fusion value of the four natural sections in 30 minutes.

Table 2. The Speed Lists of Four Natural Sections

\begin{tabular}{|c|c|c|c|c|}
\hline moment & $\begin{array}{c}\text { the speed of first } \\
\text { natural } \\
\text { section }(\mathrm{km} / \mathrm{h})\end{array}$ & $\begin{array}{l}\text { the speed of second } \\
\text { natural section }(\mathrm{km} / \mathrm{h})\end{array}$ & $\begin{array}{l}\text { the speed of third } \\
\text { natural section }(\mathrm{km} / \mathrm{h})\end{array}$ & $\begin{array}{l}\text { the speed of fourth } \\
\text { natural section }(\mathrm{km} / \mathrm{h})\end{array}$ \\
\hline 10:01 & 91 & 109 & 104 & 98 \\
\hline 10:02 & 89 & 117 & 87 & 97 \\
\hline 10:03 & 98 & 96 & 70 & 70 \\
\hline 10:04 & 85 & 96 & 97 & 97 \\
\hline 10:05 & 70 & 98 & 84 & 84 \\
\hline 10:06 & 97 & 83 & 65 & 65 \\
\hline 10:07 & 84 & 70 & 98 & 70 \\
\hline 10:08 & 65 & 96 & 97 & 97 \\
\hline 10:09 & 98 & 103 & 70 & 84 \\
\hline $10: 10$ & 97 & 101 & 97 & 65 \\
\hline 10:11 & 70 & 88 & 84 & 97 \\
\hline $10: 12$ & 97 & 75 & 65 & 84 \\
\hline $10: 13$ & 84 & 91 & 70 & 65 \\
\hline $10: 14$ & 65 & 89 & 97 & 85 \\
\hline $10: 15$ & 70 & 98 & 84 & 83 \\
\hline $10: 16$ & 97 & 85 & 65 & 70 \\
\hline $10: 17$ & 84 & 70 & 97 & 96 \\
\hline 10:18 & 65 & 97 & 84 & 103 \\
\hline 10:19 & 97 & 84 & 65 & 101 \\
\hline $10: 20$ & 84 & 65 & 85 & 88 \\
\hline 10:21 & 65 & 98 & 96 & 75 \\
\hline 10:22 & 85 & 97 & 103 & 91 \\
\hline $10: 23$ & 92 & 70 & 101 & 89 \\
\hline 10:24 & 63 & 97 & 88 & 98 \\
\hline $10: 25$ & 78 & 84 & 75 & 85 \\
\hline 10:26 & 110 & 65 & 91 & 70 \\
\hline $10: 27$ & 98 & 70 & 89 & 97 \\
\hline $10: 28$ & 108 & 97 & 98 & 84 \\
\hline 10:29 & 92 & 84 & 85 & 65 \\
\hline 10:30 & 95 & 65 & 70 & 65 \\
\hline
\end{tabular}


Assume that $\mu \mathrm{T}, \mathrm{L} 1=0.3 ; \mu \mathrm{T}, \mathrm{L} 2=0.3 ; \mu \mathrm{T}, \mathrm{L} 3=0.3 ; \mu \mathrm{T}, \mathrm{L} 4=0.1$, then at each point in time, the release speed is,

Table 3. Speed Lists of Natural Section and Release Section

\begin{tabular}{|c|c|c|c|c|c|}
\hline moment & $\begin{array}{c}\text { the speed of first } \\
\text { natural } \\
\text { section }(\mathrm{km} / \mathrm{h})\end{array}$ & $\begin{array}{l}\text { the speed of } \\
\text { second natural } \\
\text { section }(\mathrm{km} / \mathrm{h})\end{array}$ & $\begin{array}{l}\text { the speed of } \\
\text { third natural } \\
\text { section }(\mathrm{km} / \mathrm{h})\end{array}$ & $\begin{array}{c}\text { the speed of } \\
\text { fourth natural } \\
\text { section }(\mathrm{km} / \mathrm{h})\end{array}$ & $\begin{array}{c}\text { the speed of } \\
\text { release } \\
\text { section }(\mathrm{km} / \mathrm{h})\end{array}$ \\
\hline 10:01 & 91 & 109 & 104 & 98 & 101 \\
\hline 10:02 & 89 & 117 & 87 & 97 & 97.6 \\
\hline 10:03 & 98 & 96 & 70 & 70 & 86.2 \\
\hline 10:04 & 85 & 96 & 97 & 97 & 93.1 \\
\hline 10:05 & 70 & 98 & 84 & 84 & 84 \\
\hline 10:06 & 97 & 83 & 65 & 65 & 80 \\
\hline 10:07 & 84 & 70 & 98 & 70 & 82.6 \\
\hline 10:08 & 65 & 96 & 97 & 97 & 87.1 \\
\hline 10:09 & 98 & 103 & 70 & 84 & 89.7 \\
\hline $10: 10$ & 97 & 101 & 97 & 65 & 95 \\
\hline 10:11 & 60 & 58 & 54 & 67 & 58.3 \\
\hline $10: 12$ & 57 & 55 & 65 & 54 & 58.5 \\
\hline $10: 13$ & 84 & 71 & 70 & 65 & 74 \\
\hline 10:14 & 65 & 69 & 77 & 55 & 68.8 \\
\hline $10: 15$ & 70 & 68 & 84 & 83 & 74.9 \\
\hline $10: 16$ & 67 & 65 & 65 & 70 & 66.1 \\
\hline $10: 17$ & 84 & 70 & 97 & 96 & 84.9 \\
\hline 10:18 & 55 & 47 & 54 & 103 & 57.1 \\
\hline 10:19 & 97 & 84 & 65 & 101 & 83.9 \\
\hline 10:20 & 84 & 65 & 85 & 88 & 79 \\
\hline 10:21 & 65 & 98 & 96 & 75 & 85.2 \\
\hline $10: 22$ & 85 & 97 & 103 & 91 & 94.6 \\
\hline $10: 23$ & 92 & 70 & 101 & 89 & 87.8 \\
\hline 10:24 & 63 & 97 & 88 & 98 & 84.2 \\
\hline 10:25 & 78 & 84 & 75 & 85 & 79.6 \\
\hline 10:26 & 110 & 65 & 91 & 70 & 86.8 \\
\hline 10:27 & 98 & 70 & 89 & 97 & 86.8 \\
\hline $10: 28$ & 108 & 97 & 98 & 84 & 99.3 \\
\hline 10:29 & 92 & 84 & 85 & 65 & 84.8 \\
\hline $10: 30$ & 95 & 65 & 70 & 65 & 75.5 \\
\hline 10:31 & 107 & 97 & 97 & 98 & 100.1 \\
\hline $10: 32$ & 112 & 84 & 84 & 97 & $\begin{array}{l}93.7 \\
\end{array}$ \\
\hline $10: 33$ & 106 & 65 & 65 & 70 & 77.8 \\
\hline 10:34 & 92 & 85 & 98 & 97 & 92.2 \\
\hline $10: 35$ & 87 & 92 & 97 & 84 & 91.2 \\
\hline $10: 36$ & 98 & 63 & 70 & 97 & 79 \\
\hline 10:37 & 97 & 91 & 97 & 84 & 93.9 \\
\hline $10: 38$ & 70 & 89 & 84 & 65 & 79.4 \\
\hline $10: 39$ & 97 & 98 & 97 & 85 & 96.1 \\
\hline 10:40 & 84 & 85 & 84 & 92 & 85.1 \\
\hline 10:41 & 65 & 70 & 65 & 63 & 66.3 \\
\hline 10:42 & 70 & 97 & 85 & 70 & 82.6 \\
\hline 10:43 & 97 & 84 & 92 & 97 & 91.6 \\
\hline 10:44 & 84 & 65 & 63 & 84 & 72 \\
\hline 10:45 & 65 & 98 & 78 & 65 & $\begin{array}{l}78.8 \\
\end{array}$ \\
\hline
\end{tabular}




\begin{tabular}{|c|c|c|c|c|c|}
\hline moment & $\begin{array}{c}\text { the speed of first } \\
\text { natural } \\
\text { section(km/h) }\end{array}$ & $\begin{array}{c}\text { the speed of } \\
\text { second natural } \\
\text { section(km/h) }\end{array}$ & $\begin{array}{c}\text { the speed of } \\
\text { third natural } \\
\text { section(km/h) }\end{array}$ & $\begin{array}{c}\text { the speed of } \\
\text { fourth natural } \\
\text { section(km/h) }\end{array}$ & $\begin{array}{c}\text { the speed of } \\
\text { release } \\
\text { section(km/h) }\end{array}$ \\
\hline $10: 46$ & 97 & 97 & 110 & 97 & 100.9 \\
\hline $10: 47$ & 84 & 70 & 97 & 84 & 83.7 \\
\hline $10: 48$ & 65 & 97 & 84 & 65 & 80.3 \\
\hline $10: 49$ & 85 & 84 & 65 & 85 & 78.7 \\
\hline $10: 50$ & 92 & 65 & 70 & 92 & 77.3 \\
\hline $10: 51$ & 63 & 70 & 97 & 63 & 75.3 \\
\hline $10: 52$ & 78 & 97 & 84 & 78 & 85.5 \\
\hline $10: 53$ & 110 & 84 & 65 & 110 & 88.7 \\
\hline $10: 54$ & 98 & 65 & 92 & 97 & 86.2 \\
\hline $10: 55$ & 108 & 97 & 95 & 84 & 98.4 \\
\hline $10: 56$ & 92 & 84 & 91 & 65 & 86.6 \\
\hline $10: 57$ & 95 & 65 & 89 & 85 & 83.2 \\
\hline $10: 58$ & 107 & 85 & 98 & 85 & 95.5 \\
\hline $10: 59$ & 112 & 92 & 85 & 92 & 95.9 \\
\hline $11: 00$ & 106 & 63 & 70 & 84 & 80.1 \\
\hline
\end{tabular}

According to the above analysis, there is a general traffic jam at 10:11 and 10:12, which is caused by a half lane of road maintenance from seeing through camera. At 10:18, there is vehicle slow caused by the throwing things from a truck. The rest of the time is smooth. The information released on the LED is as follows:

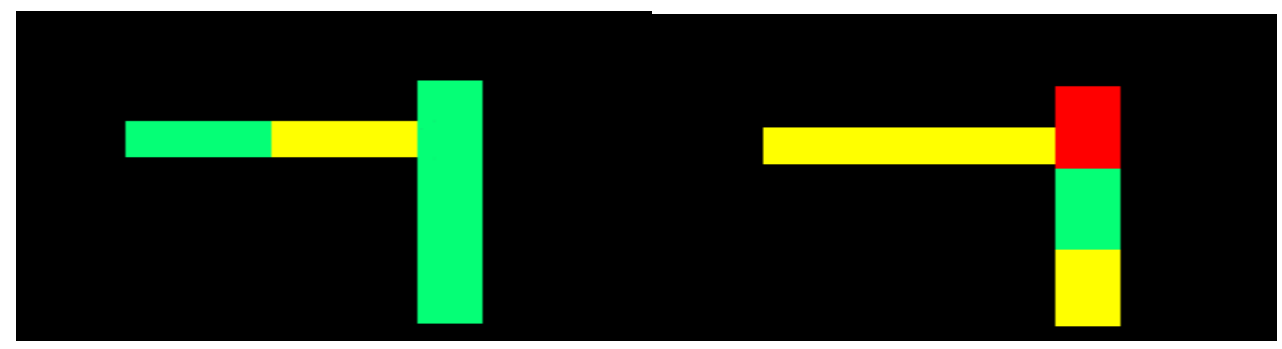

Fig 2. Traffic Status Map Shown on Led

\section{Conclusion}

This paper puts forward a method of distinguishing the highway network state, which is two times the weighted average model algorithm, and according to the road conditions of highway in Yunnan Province, the actual application results show that the method has high accuracy, figure -2 is traffic state figure of the ahead and surrounding road released real-time information display on LED. On condition of vehicle detector and video event detector work, the accuracy of the two weighted average model algorithm depends on the adjustment parameter. This algorithm is not affected by the definition of publishing section.

\section{References}

[1]. Dong Chunjiao, Shao Chunfu and so on, Identification of traffic state variation trend in road network. Shanghai, Journal of Tongji University (NATURAL SCIENCE), Vol.40 No.9, Sep. 2012.

[2]. Payne H J, Tignor S C.Freeway incident-detection algorithmsbased on decision trees withstatesU5.Transportation Research Record 682, 1978:30.

[3]. CaiHuisheng, theory and practice of traffic control [M]. Taipei: Sheng synthesis press, 1990. 
[4]. Duan Qing, Zhao Jianguo and so on.Discussion on methods of Urban Road Traffic Condition Identification, 2012.

[5]. Lin Qun, GuanZhichao and so on,,Research of applications in the identification technology of shenzhen urban road traffic conditions, The second annual conference on Intelligent Transportation,2006.

[6]. Wang Guanghui, study on the discriminant method of highway traffic operation state. Master's thesis, Jilin University 2015.

[7]. Yang Xiaoguang, Manual of urban traffic design [M]. Beijing: People's transportation press, 2003.

[8]. Wang Dianhai, traffic flow theory [M]. Beijing: People's transportation press, 2002.

[9]. Yu Quan, Feng Zhulin and so on, Study on the recognition model of highway traffic state. Journal of transportation engineering and information, No 2Vol 13, 2015. 